\title{
EVALUASI PERANGKAT LUNAK APLIKASI SHIPMENT TRACKING PADA TINGKAT PENERIMAAN PENGGUNA AKHIR
}

\author{
Agus Pamuji \\ Fakultas Teknik Dan Ilmu Komputer, Program Studi Informatika \\ Universitas Indraprasta PGRI \\ Email: jurnal.agus.pamuji@gmail.com \\ Purni Munah Hartuti \\ Fakultas Teknik Dan Ilmu Komputer, Program Studi Informatika \\ Universitas Indraprasta PGRI \\ Email: purniibunyahanum@yahoo.co.id
}

\begin{abstract}
ABSTRAK
Saat ini teknologi perangkat lunak mengalami perubahan dimulai dari perancangan, uji coba, implementasi sampai pada akhir yaitu evaluasi. Kondisi ini juga diikuti dengan tuntutan kualitas perangkat lunak yang di hasilkan oleh beberapa perusahaan pengembang. Khususnya dalam mengevaluasi perangkat lunak dalam faktor penggunaan yang di uji pada sisi eksternal yang dilakukan oleh pengguna. Studi kasus ini dilakukan untuk mengetahui faktorfaktor yang dapat mempengaruhi penggunaan aplikasi pelacakan barang. Evaluasi kasus ini dilakukan secara empirik dengan menggunakan model penerimaan teknologi yang dimodifikasi. Model ini melibatkan tujuh konstruk parameter sebagai metrik uji untuk mengukur tingkat penggunaan bersamaan dengan hipotesis yang diusulkan. Selain itu, perolehan data berasal dari 120 responden yang tersebar diwilayah Jabodetabek. Hasil Akhir menunjukan bahwa model yang diusulkan memberikan penjelasan hampir semua konstrak dan hipotesi memiliki nilai positif. Nilai tersebut mengindikasikan bahwa aplikasi pelacakan pengiriman barang dipengaruhi secara kuat oleh faktor kemudahan dan nilai kegunaan aplikasi yang bermula dari rasa percaya, kepuasan, serta norma subjektif.
\end{abstract}

Kata kunci: evaluasi; pelacakan barang; PEOU; PU; kepercayaan, kepuasan.

\section{ABSTRACT}

Today, the software technology are growing and will increasing many change. It's starting from design, testing, implementation to the end of phase that is evaluation. These conditions were also followed by the demands of software quality produced by several developer companies. Particularly in evaluating activity, the software on the usage factor being tested on the external side performed by the end-user. This case study was conducted to determine the factors that may affect the use of goods tracking applications. The evaluation of this case was done empirically using a modified technology acceptance model. This model involves seven parameter constructs as test metrics to measure the level of use with the proposed hypothesis. In addition, data acquisition comes from 120 respondents spread in Jabodetabek region. The Final Result shows that the proposed model gives an explanation of almost all the constants and hypothetes having a positive value. The value indicates that the delivery of goods delivery application is strongly influenced by the perceived ease of use factor and perceived usefulness application value that stems from trust, satisfaction, and subjective norms.

Keywords: evaluation; tracking of goods; PEOU; PU; trust, satisfaction.

\section{PENDAHULUAN}

Saat ini, hampir semua kegiatan atau aktifitas yang dilakukan oleh perusahaan sangat bergantung pada keberadaan peran perangkat lunak [1]. Perangkat lunak saat ini menjadi tuntutan bagaimana perangkat tersebut mempunyai kualitas dan daya saing yang tinggi. Oleh sebab itu, perangkat lunak perlu di evaluasi [2], [3] dan diukur [4] sebagai bentuk [5] untuk upaya [6], [7] memperbaiki kualitas [8]. Evaluasi perangkat lunak memberikan gambaran [9] untuk mengusulkan atas perbaikan proses [10], pengurangan waktu [11], hemat biaya [12], [13]. Disamping itu, evaluasi perangkat lunak merupakan suatu metode membantu perusahaan untuk dapat mengatur strategi [1], [14] manajemen perangkat lunak lebih baik disamping memperbaiki pengembangan produk, proses, dan sebagainya [15].

Hakikat dari konteks evaluasi berperan sebagai alat bantu menguji secara kuantitas dalam tingkat penerimaan teknologi atau perangkat lunak. Oleh sebab itu, pertanyaan akan muncul faktor apa yang dapat mempengaruhi 
tingkat penggunaan [16]-[18]. Pertanyaan ini dapat dijawab, kami mengembangkan model [19] dan mengujinya [20] dalam upaya menjelaskan tingat penerimaan perangkat lunak [21] pada tingkat pengguna akhir [22]. Penelitian ini berkontribusi terhadap metode yang lama dengan mengembangkan model penerimaan teknologi [29] yang awalnya dikemukakan oleh Davis (1989) [19] yang telah dimodifikasi. Model evaluasi berbasis pada Technology Acceptance Model [23], [24] memiliki dua konstruk [25] utama yaitu persepsi kegunaan dan persepsi kemudahan menggunakan [26].

Terkait dengan evaluasi perangkat lunak, kami melakukan eksperimen besar pada beberapa perusahaan yang menyediakan fitur atau aplikasi pelacakan pengiriman barang yang dijalan melalui web browser atau berbasis mobile[27] . Aplikasi pelacakan barang diperuntukan semua pengguna untuk memantau status pengiriman barang, lokasi atau posisi barang sebelum barang sampai pada lokasi tujuan. Faktanya, aplikasi yang diterapkan pada umumnya berbasis web meskipun sebagian sudah terintegrasi dengan layanan mobile [28], [29]-[31]. Di samping itu, aplikasi yang digunakan bersifat real-time [28][27] dimana aplikasi sudah pernah diteliti sebelumnya dan diterapkan pada bidang transportasi seperti bus ; kereta; dan lain-lain [32], [33]. Karakteristik aplikasi pelacakan barang yaitu mampu mengidentifikasi dan analisa lokasi serta dapat mengestimasi waktu kedatangan; keterlambatan suatu kendaraan atau barang. Kemampuan tersebut didukung dengan teknologi Global Positioning System [34]. Tujuan pada studi kasus ini kami akan menganalisa faktor-faktor apa saja yang dapat mempengaruhi tingkat penerimaan [22] serta adopsi [35] terhadap perangkat lunak dan menemukan teori [36] sebagai kontribusi perbaikan aktifitas uji coba perangkat lunak [37] khususnya evaluasi pada tingkat pengguna [38]. Pada makalah ini akan diorganisasikan yaitu pendahuluan mengenai latar belakang penelitiaan serta studi kasus terkait; metodologi penelitian yang menjelaskan model dan hipotesis yang akan digunakan; dan hasil serta pembahasan sebagai analisis evaluasi perangkat lunak, khususnya aplikasi shipment tracking.

\section{METODOLOGI PENELITIAN}

Dalam upaya mengembangkan dan menguji model penerimaan teknologi yang diusulkan, maka akan dilakukan langkah-langkah penelitian yaitu : (1) identifikasi masalah dan fenomena yang ada pada penggunaan aplikasi shipment tracking, (2) perumusan hipotesis, (3) pengumpulan sumber data dan informasi, (4) pengolahan data dan analisis.

\subsection{Teknik Studi Kasus}

Terkait dengan tipe studi kasus ini dikategorikan sebagai pengkajian pada sisi kuantitatif [48] dengan menggunakan model penerimaan teknologi [39], [40]. Pada model ini akan dianalisis faktor - faktor yang berpengaruh secara signifikan terhadap penggunaan aplikasi shipment tracking berbasis mobile [41] . Studi kasus ini dilakukan dengan mendapatkan informasi melalui cara observasi, angket, dan kuisioner yang diperoleh dari objek penelitian serta yang terlibat didalam penelitian. Pengumpula melalui kuesioner akan dilakukan instrumen termasuk validitas dan reabilitas dalam upaya keabsahan sebuah data.

\subsection{Objek Penelitian}

Objek studi kasus pengkajian ini berbentuk aplikasi sebagai perangkat lunak dan pengguna yang menggunakan aplikasi [42] pelacakan pengiriman barang berbasis web [36] maupun mobile. Terkait dengan penelitian ini, objek yang digunakan adalah fitur yang terdapat pada apliksi untuk pelacakan pengiriman barang. Selain dengan aplikasi yang digunakan juga melibatkan empat penyedia jasa yang beroperasi dibidang jasa pengiriman barang dengan responden yang tersebar diwilayah Jakarta, Bogor, Depok, Tangerang, dan Bekasi. Pengambilan atau pengumpulan data terkait dengan studi kasus ini dimulai sejak Maret sampai Mei 2018. Selanjutnya, informasi yang sudah dikumpulkan dipergunakan dalam menganalisa kasus ini menggunakan data tingkat pertama ketika informasi diberikan oleh peserta sebagai objek penelitian yang mengisi form atau lembar kuesioner baik secara tertulis maupun daring. Responden yang mengisi lembar kuesioner adalah orang yang berpengalaman atau pernah mengirim barang melalui jasa ekspedisi barang dan menggunakan aplikasi dan fitur pelacakan barang.

\subsection{Model dan Hipotesis Penelitian}

Menurut teori yang diadopsi dari TAM [43] model ini sudah diterapkan secara meluas sebagai sarana memprediksi serta menjelaskan tingkah laku [44] para pengguna begitupula dengan pengguna teknologi infornasi. Penggunaan terhadap sistem; teknologi; perangkat lunak ditentukan [45] dengan perilaku [40] atau tingkah laku secara personal disamping merujuk pada minat perilaku untuk menggunakan. Hakikatnya ada dua faktor penentu yaitu persepsi kemudahan penggunaan (Perceived ease of use) dan persepsi kgunaan (Perceived Usefulness). Kasus ini dikaji dengan mengajukan atribut trust [30] ; user satisfaction [46], subjective norm, sebagaimana kami sajikan pada gambar dibawah ini : 


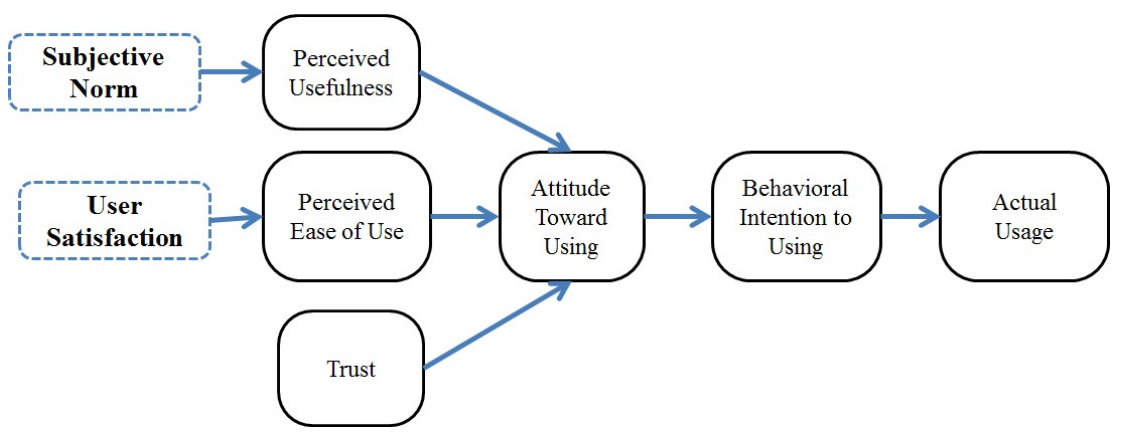

Gambar 1. Model Penelitian Evaluasi Perangkat Lunak

Model yang ada diatas akan dijelaskan melalui hipotesis yang diusulkan sebagai berikut :

H1 : norma subjektif akan berpengaruh kuat pada persepsi kegunaan

$\mathrm{H} 2$ : kepuasan pengguna akan berpengaruh kuat pada persepsi kemudahan penggunaan

$\mathrm{H} 3$ : kepercayaan akan berpengaruh kuat pada sikap pengguna

H4 : persepsi kemudahan penggunaan akan berpengaruh kuat pada sika pengguna

H5 : persepsi kegunaan akan berpengaruh kuat pada sikap pengguna

H6 : sikap pengguna akan berpengaruh kuat pada minat perilaku menggunakan

$\mathrm{H} 7$ : minat perilaku menggunakan berpengaruh kuat pada pengguna nyata

\subsection{Struktur Dan Perancangan Instrumen}

Berikut ini adalah struktur instrumen penelitian terkait kasus pelacakan pengiriman barang. Hal - hal yang dilakulan oleh peneliti didalam melakukan teknik analisa penelitian ini yaitu menyebarkan instrumen sebagai alat bantu penelitian pada sampel yang sudah ditentukan. Instrumen yang akan diterapkan adalah dalam bentuk angket atau kuesioner. Lembar kuesioner yang akan didistrubusikan terdiri dalam 2 bagian, yaitu informasi identitas responden dan daftar pertanyaan yang dikelompokan dalam variabel tertentU. Data yang dikumpulkan berasal dari setiap responden akan diolah dengan bantuan perangkat lunak LISREL.

Tabel 1. Perancangan instrumen penelitian

\begin{tabular}{|c|c|c|}
\hline Item Konstruk & Kode Pernyataan & Ukuran Permasalahan \\
\hline \multirow[t]{3}{*}{ PEOU } & $X 1$ & Aplikasi pelacakan mudah diakses \\
\hline & $X 2$ & Tampilan aplikasi mudah dipahami \\
\hline & $X 3$ & Susunan menu pelacakan mudah dipelajari \\
\hline \multirow[t]{3}{*}{ PU } & $X 4$ & Aplikasi pelacakan memberikan informasi jelas \\
\hline & $X 5$ & Saya merasa terbantu dengan aplikasi pelacakan \\
\hline & X6 & Aplikasi pelacakan sangat membantu saya \\
\hline \multirow[t]{2}{*}{ TRUST } & $X 7$ & Saya percaya informasi status barang akurat \\
\hline & $X 8$ & Saya percaya akan kenyamanan akses informasi \\
\hline \multirow[t]{2}{*}{ US } & $X 9$ & Saya merasa puas atas informasi pada aplikasi pelacakan barang \\
\hline & $X 10$ & $\begin{array}{l}\text { Saya puas dengan aplikasi pelacakan karena mudah digunakan } \\
\text { Saya akan menggunakan aplikasi pelacakan barang jika ada orang }\end{array}$ \\
\hline \multirow[t]{2}{*}{ SN } & $X 11$ & lain dahulu memakainya \\
\hline & $X 12$ & $\begin{array}{l}\text { Saya lebih selnag memakai aplikasi jika bersama dengan } \\
\text { pengguna lain }\end{array}$ \\
\hline \multirow[t]{2}{*}{ ATU } & $X 14$ & $\begin{array}{l}\text { Aplikasi pelacakan memberikan jaminan informasi } \\
\text { Saya merasa percaya diri menggunakan aplikasi pelacakan }\end{array}$ \\
\hline & $X 15$ & barang \\
\hline \multirow[t]{2}{*}{ BITU } & $X 16$ & $\begin{array}{l}\text { Saya mengakses aplikasi pelacakan barang setiap hari } \\
\text { Saya selalu mendapat untung bila menggunakan aplikasi }\end{array}$ \\
\hline & $X 17$ & $\begin{array}{l}\text { pelacakan barang } \\
\text { Saya selalu mengakses aplikasi walaupun tidak ada pengiriman }\end{array}$ \\
\hline \multirow[t]{2}{*}{ ASU } & $X 18$ & barang \\
\hline & $X 19$ & Rata-rata akases aplikasi hampir lebih 15 menit \\
\hline
\end{tabular}

Berdasarkan tabel diatas, setiap kode pernyataan dikelompokan kedalam tiap variabel konstruk. Salah satunya adalah X1,X2, dan X3 dkelompokan kedalam variabel PEOU. Variabel ini menggambarkan kemudahan yang 
dialami oleh pengguna saat menggunakan aplikasi. Kemudahan yang dialami pengguna direpresentasikan pada pernyataan kemudahan akses aplikasi, pengguna dapat memahami dan mempelajari aplikasi, serta susunan menu yang sistematis disajikan dalam tampilan interaktif. Selanjutnya variabel PU, dimana variabel ini menjelaskan kegunaan yang diterima oleh pengguna yang direpresentasikan dengan pernyataan tentang manfaat atau kegunaan aplikasi yang membantu setiap pengguna disaat mencari atau melacak posisi serta status pengiriman barang. Begitu pula dengan variabel TRUST yang terdiri dari dua pernyataan X7 dan X8 dan seterusnya.

\section{HASIL DAN PEMBAHASAN}

\subsection{Deskripsi Data dan Informasi Demografi Responden}

Tahap awal dilakukan melalui deskripsi data terkait dengan model yang digunakan. Deskripsi data meliputi nilai mean, median, mode dan standar deviasi yang dijelaskan pada tabel dibawah ini. Berdasarkan tabel dibawah ini, hampir sebagian rata-rata terbesar pada variabel ASU dimana variabel ini menggambarkan tingkat penggunaan nyata menjadi penentu. Variabel ini bernilai 11,98 lebih unggul dibandingkan dengan variabel lain. Sedangkan diurutan kedua adalah variabel ATU, dimana variabel ini merepresentasikan sikap untuk menggunakan dengan nilai 9,16 yang menjadi penentu untuk menjadi pengguna nyata.

Tabel 2. Deskripsi data

\begin{tabular}{lllll}
\hline Variabel & Mean & Median & Mode & Std. Deviasi \\
\hline PEOU & 8,69 & 8,00 & 8 & 2,248 \\
PU & 9,01 & 9,00 & 8 & 2,431 \\
ATU & 9,16 & 9,00 & 8 & 2,373 \\
ASU & 11,98 & 12,00 & 11 & 2,682 \\
TRUST & 7,85 & 7,05 & 8 & 2,701 \\
USER SATISFACTION & 8,12 & 8,00 & 11 & 2,217 \\
SUBJECTIVE NORM & 8,40 & 9,00 & 11 & 2,494 \\
\hline
\end{tabular}

Selanjutnya, berikut ini dijelaskan demografi respoden yang digunakan ketika melakukan pengumpulan data.

Tabel 3. Informasi demografi responden dalam \%

\begin{tabular}{lrlr}
\hline Jenis Kelamin & \multicolumn{3}{c}{ Lokasi Sampel } \\
\hline Pria & 86 & Jakarta & 24 \\
Wanita & 34 & Bogor & 21 \\
Total & 100 & Depok & 18 \\
& & Tangerang & 31 \\
\cline { 1 - 1 } Pendidikan & & Bekasi & 26 \\
\cline { 1 - 1 } SMA/sederajat & 18 & Total & 100 \\
Diploma & 34 & & \\
\cline { 3 - 4 } Strata 1 & 45 & Status Aktifitas & 26 \\
Strata 2 & 10 & Karyawan & 12 \\
Strata 3 & 12 & Mahasiswa & 41 \\
Tidak Sekolah & 1 & Wirausaha & 31 \\
Total & 100 & Mengurus Rumah Tangga & 10 \\
& & Lain-lain & 100 \\
\hline
\end{tabular}

Semua data dikumpulkan melalui survei dan observasi ke beberapa wilayah JABODETABEK serta titik pusat atau agen pengiriman barang. Berdasarkan data yang diperoleh adalah data yang disajikan pada tabel diatas. Pengumpulan sampel terbesar berada diwilayah Tangerang kemudian Jakarta baik Jakarta Barat, Jakarta Timur dan Jakarta Selatan. Setiap orang yang mengirimkan barang dan memakai aplikasi untuk mengecek barang dilakukan oleh wirausahawan dimana mereka memiliki toko untuk menjalankan bisnis sekaligus berjualan secara daring terlihat perolehan sebanyak 41. Walaupun demikian, kondisi ini tidak bisa lepas dengan faktor jenis kelamin dimana sebagian besar pelaku nya adalah pria.

\subsection{Uji Validitas}

Instrumen yang sudah dirancang sebagai alat ukur akan diuji absahannya melalui uji validitas, dimana alat ukur ini dapat dikatakan valid atau tidak valid. Hasil pengukuran dapat diketahui dengan membandingkan indeks korelasi product momen Pearson pada tingkat 5\% beserta nilai tabel $\mathrm{r}$. Para peneliti sebelumnya memberikan rekomendasi hal ini selanjutnya bila nilai $\mathrm{r}$ hitung lebih besar dari $\mathrm{r}$ tabel maka item dianggap valid begitu pula 
sebaliknya apabila lebih rendah dari $r$ tabel maka dianggap tidak valid. Pada kasus ini dapat diketahui bahwa nilai sampel $\mathrm{N}$ sebanyak 40 sedangkan nilai $\mathrm{r}$ tabel nya adalah 0,320 .

Tabel 4. Hasil uji instrumen variabel konstruk

\begin{tabular}{lllll}
\hline Item & $\boldsymbol{R}$ & Sig. & Status Item & Variabel \\
\hline$X 1$ & 0,412 & 0,000 & Valid & PEOU \\
$X 2$ & 0,361 & 0,000 & Valid & PEOU \\
$X 3$ & 0,348 & 0,000 & Valid & PEOU \\
$X 4$ & 0,512 & 0,000 & Valid & PU \\
$X 5$ & 0,610 & 0,000 & Valid & PU \\
$X 6$ & 0,591 & 0,000 & Valid & PU \\
$X 7$ & 0,358 & 0,000 & Valid & TRUST \\
$X 8$ & 0,677 & 0,000 & Valid & TRUST \\
$X 9$ & 0,419 & 0,000 & Valid & US \\
$X 10$ & 0,394 & 0,000 & Valid & US \\
$X 11$ & 0,372 & 0,000 & Valid & SN \\
$X 12$ & 0,364 & 0,000 & Valid & $S N$ \\
$X 13$ & 0,714 & 0,000 & Valid & $S N$ \\
$X 14$ & 0,540 & 0,000 & Valid & $A T U$ \\
$X 15$ & 0,403 & 0,000 & Valid & $A T U$ \\
$X 16$ & 0,601 & 0,000 & Valid & BITU \\
$X 17$ & 0,510 & 0,000 & Valid & BITU \\
$X 18$ & 0,553 & 0,000 & Valid & $A S U$ \\
$X 19$ & 0,231 & 0,000 & Valid & $A S U$ \\
\hline
\end{tabular}

$\begin{array}{ll}\text { Keterangan : } \\ \text { PEOU } & \text { : Perceived Ease of Use } \\ \text { PU } & : \text { Perceived Usefulness } \\ \text { US } & \text { : User Satisfaction } \\ \text { SN } & \text { : Subjective Norm } \\ \text { ATU } & : \text { Attitude Toward Using } \\ \text { BITU } & \text { : Behavioral Intention to using } \\ \text { ASU } & : \text { Actual Usage }\end{array}$

Hampir semua item yang sudah dilakukan uji validitas melalui perangkat lunak bantu SPSS versi 20.0 dapat dinyatakan valid. Hal ini ditunjukan semua nilai memenuhi kriteria melebihi nilai $\mathrm{R}$ tabel $(0,320)$.

\subsection{Uji Reliabilitas}

Dalam memperkuat nilai validitas, maka perlu dilakukan uji reabilitas sebagai indikator untuk memeriksa dan memastikan bahwa alat ukur yang digunakan itu konsisten. Pada pengujian reabilitas hasil dari pengumpulan kuesioner menggunakan teknik Cronbach's Alpha. Sebagian peneliti menyarankan agar nilai alpha jangan melibihi 0,6. Apabila melebihi maka dapat dianggap tidak valid.

Tabel 5. Uji reliabilitas konstruk

\begin{tabular}{cccc}
\hline Item Variabel & Jumlah Item & Koefisien Alpha & Status Item \\
\hline PEOU & 3 & 0,804 & Valid \\
PU & 3 & 0,791 & Valid \\
TRUST & 2 & 0,758 & Valid \\
$U S$ & 2 & 0,701 & Valid \\
SN & 3 & 0,823 & Valid \\
$A T U$ & 2 & 0,674 & Valid \\
BITU & 2 & 0,771 & Valid \\
ASU & 2 & 0,709 & Valid \\
\hline
\end{tabular}

Hasil uji menunjukan bahwa, nilai koefisien Alpha melebihi 0,6. Nilai ini pada setiap variabel konstruk sehingga dapat dikatakan sudah konsisten atau variabel dan bisa dilanjutkan ke analisis berikutnya. 


\subsection{Uji Normalitas}

Berikutnya adalah melakukan uji normalitas dalam upaya menganalisa kedua variabel baik bebas maupun terikat dapat berdistribusi normal atau tidak. Uji normalitas melibatkan variabel konstruk PEOU, PU, TRUST, US, SN, ATU, BITU, ASU sebagaimana ditampilkan dibawah ini.

Tabel 6. Uji Normalitas Konstruk

\begin{tabular}{ccccc}
\hline Item & Kolmogorov & Sig. & \multicolumn{2}{c}{ Normal Parameter } \\
\cline { 4 - 5 } Variabel & Smirnov & $(2$ tailed $)$ & Mean & Std. Deviation \\
\hline PEOU & 0,866 & 0,271 & 18,23 & 14,325 \\
PU & 0,440 & 0,592 & 12,52 & 18,542 \\
TRUST & 0,746 & 0,451 & 16,02 & 14,120 \\
$U S$ & 0,817 & 0,813 & 18,26 & 10,152 \\
SN & 0,715 & 0,308 & 18,81 & 11,450 \\
$A T U$ & 0,717 & 0,507 & 11,54 & 13,140 \\
BITU & 0,801 & 0,587 & 15,60 & 12,149 \\
ASU & 0,709 & 0,643 & 17,06 & 17,520 \\
\hline
\end{tabular}

\section{KESIMPULAN DAN HASIL AKHIR}

Ada tujuh hipotesis yang diajukan dan sudah dilakukan uji dengan menggunakan analisis regresi ganda. Teknik analisis ini digunakan untuk mengukur besarnya pengaruh antara dua atau lebih variabel bebas terhadap variabel terikat. Adapaun hasil hipotesis nya adalah disajikan pada tabel dibawah ini.

Tabel 7. Hasil uji hipotesis

\begin{tabular}{ccc}
\hline Hipotesis & Asymtotic Significance & Keterangan \\
\hline$H 1$ & 0,203 & Signifikan \\
$H 2$ & 0,752 & Signifikan \\
$H 3$ & 0,502 & Signifikan \\
$H 4$ & 0,079 & Signifikan \\
$H 5$ & 0,032 & Signifikan \\
$H 6$ & 0,0610 & Signifikan \\
$H 7$ & 0,073 & Signifikan \\
\hline
\end{tabular}

Berdasarkan tujuh hipotesis yang diajukan hampir semua signifikan. Hal ini menggambarkan bahwa aplikasi pelacakan barang hanya bisa dipakai dari aspek norma subjektif, kepuasan pengguna, kepercayaan, kemudahan dalam akses, kegunaan, sikap, dan minat perilaku menggunakan. Seorang penggna akan terpengaruh untuk menggunaakan apabila pengguna tersebut mendapat rekomendasi dari temannya atau orang disekeliling untuk mengecek posisi barang dimana pengguna tersebut ingin mengetahui lebih detail setiap informasi pengiriman barang. Walaupun pengguna tersebut didorong oleh pengguna lain, juga pengguna merasa percaya dan yakin bahwa informasi yang disampaikan itu akurat sehingga pengguna merasa puas dengan pelayanan akses informasi pengiriman barang yang ada pada aplikasi pelacakan barang. Disamping iu, pengguna merasa terbantu dengan kemudahan akses serta nilai kegunaan aplikasi. Oleh sebab itu, perilaku pengguna menjadi penentu untuk menilai bahwa pengguna menjadi kunci bahwa perangkat lunak itu sukses meskipun mengalami fase dan uji coba yang kompleks. Diakhir makalah ini, kami akan memberikan gambaran bagaimana TAM yang sudah mengalami banyak perubahan dan pengembangan. Saat ini TAM kami adopsi untuk uji dan evaluasi perngkat lunak disebabkan untuk mengukur seberapa jauh tingkat penerimaan.

Pada kasus ini juga perlu dikaji dan dikembangkan kembali pada penelitian selanjutnya bagaimana menganalisa tingkat penolakan pengguna untuk menggunakan apabila pengguna merasa tidak nyaman yang berakibat stress. Kasus ini sebagai sisi dampak negatif pemanfaatan teknologi informasi dan juga sedikit perhatian dari para peneliti.

\section{DAMPAK PENELITIAN}

Aktifitas dan pengkajian yang dilakukan dalam rangka mengukur dan menganalisa tingkat penerimaa, maka kami dapat menemukan suatu kontribusi terhadap perkembangan metode uji coba perangkat lunak khususnya evaluasi walaupun juga bersamaan dengan berkembangnya model TAM. Penerapan model penerimaan akan menjadi titik awal untuk dapat dilakukan audit secara eksternal yang 
berada pada posisi pengguna akhir walaupun perangkat lunak itu sudah diuji oleh tim penguji yang berasal dari luar perusahaan. Oleh sebab itu, evaluasi ini akan membentuk pola evaluasi perangkat lunak berbasis tingkah laku yang melibatkan beberapa konstruk yang terkait.

\section{DAFTAR PUSTAKA}

[1] Y. Singh, Software Testing. Cambridge: Cambridge Press, 2012.

[2] B. Hambling and P. van Goethem, User Acceptance Testing: A Step-by-Step Guide. Swindon: BCS Learning and Development, 2013.

[3] A. Ahmed, Software Testing as Service. Boca Raton: CRC Press, 2010.

[4] B. A. Wulan and B. Soedijono, "Evaluasi Penerimaan Bio Sistem Online Menggunakan Pendekatan Technology Acceptance Model (TAM)," J. Teknol. Inf., vol. 12, no. 34, pp. 26-37, 2017.

[5] C. Korunka and P. Hoonakker, The Impact of ICT on Quality of Working Life. London: Springer, 2014.

[6] R. Peng, L. Xiong, and Z. Yang, "Exploring Tourist Adoption of Tourism Mobile Payment: An Empirical Analysis," J. Theor. Appl. Electron. Commer. Res., vol. 7, no. 1, pp. 21-33, 2012.

[7] I. M. Klopping and E. Mc Kinney, "Extending the Technology Acceptance Model and the Task Technology Fit Model to Consumer E - Commerce," Inf. Technol. Learn. Perform. J., vol. 22, no. 1, pp. 35-48, 2004.

[8] R. S. Pressman, Software Engineering A Practitioner's Approach. Boston: McGrawHill, 2001.

[9] N. Fathema, D. Shannon, and M. Ross, "Expanding The Technology Acceptance Model ( TAM ) to Examine Faculty Use of Learning Management Systems ( LMSs ) In Higher Education Institutions," MERLOT J. Online Learn. Teach., vol. 11, no. 2, pp. 210-232, 2015.

[10] R. Fayad and D. Paper, "The Technology Acceptance Model E-Commerce Extension: A Conceptual Framework," in World Conference on Business, Economics and Management, WCBEM, 2015, pp. 1000-1006.

[11] P. Jalote, A Concise Introduction to Software Engineering. Delhi: Springer, 2008.

[12] S. Y. Park, E. Technology, S. Korea, and T. Fax, "An Analysis of the Technology Acceptance Model in Understanding University Students ' Behavioral Intention to Use e-Learning Research hypotheses," Educ. Technol. Soc., vol. 12, no. 3, pp. 150-162, 2009.

[13] J. Pedro et al., "The effects of the multimodal real time information systems on the travel behaviour," in World Conference on Transport Research - WCTR, 2017, pp. 2681-2693.

[14] B. B. Agarwal, S. P. Tayal, and M. Gupta, Software Engineering and Testing. Massachusetts: Jones and Bartlett, 2010.

[15] I. Sommerville, Software Engineering. Boston: Addison-Wesley, 2011.

[16] E. Fatmawati, "Technology Acceptance Model (Tam) Untuk Menganalisis Penerimaan Terhadap Sistem Informasi Perpustakaan," J. Iqra, vol. 9, no. 1, pp. 1-13, 2015.

[17] V. N. Helia, V. I. Asri, E. Kusrini, and S. Miranda, "Modified technology acceptance model for hospital information system evaluation - a case study," in MATEC Web of Conferences, 2017, pp. $1-5$.

[18] J. Zhao, S. Fang, and P. Jin, "Modeling and Quantifying User Acceptance of Personalized Business Modes Based on TAM , Trust and Attitude," J. Sustain., vol. 10, no. 356, pp. 1-26, 2018.

[19] N. Miyono, "Analisis e-learning menggunakan technology acceptance modelling," J. Transform., vol. 11, no. 1, pp. 39-50, 2013.

[20] R. Malhotra, Empirical Research in Software Engineering. Boca Raton: CRC Press, 2016.

[21] S. Chang and S. Chang, "Using Modified TAM to Examine the Software Engineers 'Attitude on Computer Software Patents," pp. 1985-1989, 2007.

[22] L. G. Wallace and S. D. Sheetz, "Information \& Management The adoption of software measures : A technology acceptance model ( TAM ) perspective," Inf. Manag., vol. 51, no. 2, pp. 249-259, 2014.

[23] H. A. Kurniawati, W. A. Winarno, A. Arif, F. Ekonomi, and U. J. Unej, "Analisis Minat Penggunaan Mobile Banking Dengan Pendekatan Technology Acceptance Model ( TAM ) Yang Telah Dimodifikasi ( Analysis Behavioral Intention to Uses of Mobile Banking Technology Acceptance Model ( TAM ) Approach Modified )," eJurnal Ekon. Bisnis dan Akunt., vol. 4, no. 1, pp. 24-29, 2017.

[24] A. Alambaigi and I. Ahangari, "Technology Acceptance Model ( TAM ) As a Predictor Model for Explaining Agricultural Experts Behavior in Acceptance of ICT," Int. J. Agric. Manag. Dev., vol. 6, no. 2, pp. 235-247, 2016.

[25] E. P. Kusumah, "Technology Acceptance Model ( TAM ) of Statistical Package for the Social Sciences ( SPSS ) Applications,” Integr. J. Bus. Econ., vol. 2, no. 1, pp. 0-11, 2018. 
[26] Fishbein and M. Ajzen, Predicting and Changing Behavior. New York: Psychology Press, 2010.

[27] K. Liu, Y. Shen, and L. Chen, "Simple Online and Realtime Tracking with Spherical Panoramic Camera," IEEE Int. Conf. Consum. Electron., pp. 1-6, 2018.

[28] X. J. Harmony and V. V Gayah, "International Journal of Transportation Evaluation of Real-Time Transit Information Systems: An information demand and supply approach," Int. J. Transp. Sci. Technol., vol. 6, no. 1, pp. 86-98, 2017.

[29] J. Chin and S. Lin, 'Investigating Users ' Perspectives in Building Energy Management System with an extension of Technology Acceptance Model: A Case Study in Indonesian Manufacturing Companies," in The Third Information Systems International Conference, 2015, vol. 72, pp. 31-39.

[30] E. Traveloka, T. Loanata, K. G. Tileng, A. Kemajuan, and T. Informasi, "Pengaruh Trust dan Perceived Risk pada Intention To Use Menggunakan Technology Acceptance Model ( Studi Kasus Pada Situs," JUISI, vol. 2, no. 1, pp. 64-73, 2016.

[31] F. Sayekti and P. Putarta, "Penerapan Technology Acceptance Model ( Tam ) Dalam Pengujian Model Penerimaan Sistem Informasi Keuangan Daerah,” J. Manaj. Terap. Dan Teor., vol. 9, no. 3, pp. 196-209, 2016.

[32] B. Y. O. Low, S. H. Dahlan, M. Helmy, and A. Wahab, "Real-time Bus Location and Arrival Information System," in IEEE Conference on Wireless Sensors (ICWiSe), 2016, pp. 50-53.

[33] J. E. Mmari and S. Markon, "Mobile applications for real time information delivery on Rapid Bus Transit systems in Tanzania," in International Conference on Advances in ICT for Emerging Regions (ICTer), 2017, pp. 54-61.

[34] X. Xu, J. Y. L. Thong, and K. Y. Tam, "Winning Back Technology Disadopters: Testing a Technology Readoption Model in the Context of Mobile Internet Services Winning Back Technology Disadopters: Testing a Technology Readoption Model in the Context of Mobile Internet Services," J. Manag. Inf. Syst., vol. 34, no. 1, pp. 102-140, 2017.

[35] A. C. Punnoose, "Determinants of Intention to Use eLearning Based on the Technology Acceptance Model," J. Inf. Technol. Educ. Res., vol. 11, no. 1, pp. 301-337, 2012.

[36] K. Nazemi, D. Burkhardt, D. Hoppe, and M. Nazemi, "Web-based evaluation of information visualization," in 6th International Conference on Applied Human Factors and Ergonomics (AHFE 2015), 2015, pp. 5527-5534.

[37] Supriyanti and M. Cholil, "Aplikasi Technology Acceptance Model Pada Sistem Informasi Manajemen Rumah Sakit Di Rumah Sakit Ortopedi Prof. Dr. R. Soeharso Surakarta," J. Ekomomi Manaj. Sumber Daya, vol. 18, no. 1, pp. 42-51, 2016.

[38] M. Z. Tunio, H. Luo, C. Wang, and F. Zhao, "Task Assignment Model for Crowdsourcing Software Development: TAM,” J. Inf. Process. Syst., vol. 14, no. 3, pp. 621-630, 2018.

[39] Z. Hussein, "Leading to Intention: The Role of Attitude in Relation to Technology Acceptance Model in E-Learning," in IEEE Int. Symposium on Robotic and Intelegent Sensor, 2017, pp. 159164.

[40] H. Al, F. Abdallah, and K. Barbar, "Measuring Intentions among Employees toward the Use of a Balanced Scorecard and Information System : A Conceptual Approach Using the Theory of Planned Behavior and the Technology Acceptance Model," in 4th World Conference on Business, Economics and Management, WCBEM, 2015, pp. 1146-1151.

[41] B. Satya, R. Aditya, and K. Kunci, "Analisis Penerimaan (Acceptance) Penerapan Internet Sehat Dengan Technology Acceptance Model (TAM) (Studi Kasus Pada STMIK AMIKOM Yogyakarta)," J. DASI, vol. 14, no. 1, pp. 14-17, 2013.

[42] I. W. Saputra, C. W. Budiyanto, and P. Hatta, "The Development of a Competency Testing Systems: Adopting TAM to Explore User's Acceptance," Indones. J. Informatics Educ., vol. 1, no. 2, pp. 8794, 2017.

[43] A. N. Purbowo and A. I. Suryadi, "Web Based Customer Relationship Management Application for Helping Sales Analysis on Bike Manufacturer," in International Conference on Soft Computing, Intelligent System and Information Technology, 2017, pp. 347-352.

[44] W. P. Handayani and M. Harsono, "Aplikasi Technology Acceptance Model (Tam) Pada Komputerisasi Kegiatan Pertanahan,” J. Econ., vol. 12, no. 1, pp. 13-20, 2016.

[45] Devi, N. Luh, and I. Suartana, "Analisis Technology Acceptance Model ( Tam ) Terhadap Penggunaan Sistem Informasi Di Nusa Dua Beach Hotel \& Spa," E-Jurnal Akuntasi Univ. Udayana, vol. 6, no. 1, pp. 167-184, 2014.

[46] M. Pejić, A. Čeljo, and J. Zoroja, "Technology Acceptance Model for Business Intelligence Systems : Preliminary Research," in Conference on ENTERprise Information Systems / International Conference on Project, 2016, vol. 100, pp. 995-1001. 